\title{
A novel synthetic drug, LB-18, closely related to lembehyne-A derived from a marine sponge, induces caspase-independent cell death to human neuroblastoma cells
}

\author{
MORIATSU IZUMI ${ }^{1,2^{*}}$, SHINGO YOGOSAWA ${ }^{1 *}$, SHUNJI AOKI ${ }^{3}$, HIROTSUNA WATANABE $^{1}$, \\ JUN KAMIYAMA ${ }^{1}$, YOSHINORI TAKAHARA ${ }^{1}$, YOSHIHIRO SOWA ${ }^{1}$, MOTOMASA KOBAYASHI ${ }^{3}$, \\ HAJIME HOSOI $^{2}$, TOHRU SUGIMOTO ${ }^{2}$ and TOSHIYUKI SAKAI ${ }^{1}$

\begin{abstract}
Departments of ${ }^{1}$ Molecular-Targeting Cancer Prevention and ${ }^{2}$ Pediatrics, Graduate School of Medical Science, Kyoto Prefectural University of Medicine, Kawaramachi-Hirokoji, Kamigyo-ku, Kyoto 602-8566;

${ }^{3}$ Department of Biochemistry of Natural Organism, Graduate School of Pharmaceutical Sciences,

Osaka University, 1-6 Yamada-oka, Suita, Osaka 565-0871, Japan
\end{abstract}

Received December 12, 2005; Accepted February 10, 2006

\begin{abstract}
Neuroblastoma is a common solid tumor of children that arises from the sympathetic nervous system. Much work has consequently focused on the possibility of inducing marked cell death in neuroblastoma, and the new effective drugs are required. We have newly synthesized LB-18, closely related to lembehyne A (LB-A), a polyacetylene derived from a kind of marine sponge. LB-A has been shown to induce p21/WAF1 and causes G1 phase arrest in mouse neuroblastoma Neuro2A cells; however, we show here that LB-18 causes cell death in human neuroblastoma KP-N-TK cells in a dosedependent manner. TUNEL assay and flow cytometric analysis showed that the cell death caused by LB-18 was associated with the DNA damage but the pan-caspase inhibitor, zVADfmk, could not prevent the cell death. Western blot analysis and cleavage of the caspase- 3 or -7 substrate assay showed that LB-18 could not activate caspases 3, 7, 8 and 9. These results suggest that LB-18 causes caspase-independent cell
\end{abstract}

Correspondence to: Dr Toshiyuki Sakai, Department of MolecularTargeting Cancer Prevention, Graduate School of Medical Science, Kyoto Prefectural University of Medicine, Kawaramachi-Hirokoji, Kamigyo-ku, Kyoto 602-8566, Japan

E-mail: tsakai@koto.kpu-m.ac.jp

${ }^{*}$ Contributed equally

Abbreviations: DAPI, 4,6-diamidino-2-phenylindole; TUNEL, TdT-mediated dUTP-biotin nick labeling; zVAD-fmk, benzyloxycarbonyl-Val-Ala-Asp $\left(\mathrm{OCH}_{3}\right)-\mathrm{CH}_{2} \mathrm{~F} ; \mathrm{LDH}$, lactate dehydrogenase

Key words: lembehynes, LB-18, neuroblastoma, caspase-independent cell death death in human neuroblastoma cells. In the future, LB-18 may be useful for cancer therapeutics, especially for neuroblastoma.

\section{Introduction}

Neuroblastoma is a common type of childhood malignant tumor. In cases with advanced stage, complete recovery is still rare. Despite progress with various therapies, consisting of chemotherapy with hematological stem cell transplantation, surgical and radiation therapies, the prognosis of advanced neuroblastoma remains poor (1). Therefore, new therapeutic approaches involving the discovery of novel effective drugs are needed.

Aoki et al reported that lembehyne A (LB-A), a new polyacetylene alcohol derived from an Indonesian marine sponge of Haliclona sp., induces cellular differentiation in mouse neuroblastoma Neuro2A cells $(2,3)$. Also, LB-A enhanced p21/WAF1 expression, thereby causing G1 phase arrest $(3,4)$. Further, structure-activity relationship study has shown that the length of the long carbon-chain parts of the lembehynes and the stereochemistry of the hydroxyl group at the $\mathrm{C}-3$ position are very important for the induction of cellular differentiation $(5,6)$. LB-18, which is one of the synthetic lembehyne analogues with an 18 carbon-chain frame, was revealed to be the most effective in the induction of differentiation and $\mathrm{p} 21 / \mathrm{WAF} 1$ expression (6; data not shown). The structure of LB-A and LB-18 is shown in Fig. 1.

Here, we show that LB-18 induces cell death in human neuroblastoma KP-N-TK cells $(7,8)$. To investigate the effect on the cell death induced by LB-18, we performed WST-8 [2-(2-methoxy-4-nitrophenyl)-3-(4-nitrophenyl)-5-(2,4disulfophenyl)-2H-tetrazolium, monosodium salt] assay, 4,6diamidino-2-phenylindole (DAPI) staining, terminal deoxynucleotidyl transferase (TdT)-mediated dUTP nick-end labeling (TUNEL) assay, flow cytometry, Western blot analysis, and caspase-3/7 enzyme assays. KP-N-TK cells treated with LB-18 exhibited DNA degradation without caspase activation. The data show that LB-18 may induce cell death through caspase- 
A<smiles>CCCC=CCCCCCCCO</smiles>

\section{Lembehyne A (LB-A)}

B

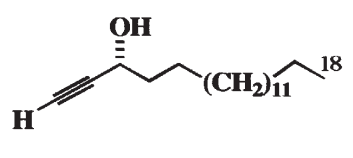

\section{LB-18}

Figure 1. The chemical structures of lembehyne A (A) and LB-18 (B).

independent pathways in human neuroblastoma KP-N-TK cells.

\section{Materials and methods}

Materials. LB-18 was synthesized and purified as described previously (5). The drug was dissolved in $100 \%$ ethanol and continuously preserved at $-20^{\circ} \mathrm{C}$. Fenretinide $[\mathrm{N}-(4-$ hydroxyphenyl) retinamide] was obtained from Toronto Research Chemicals Inc. (North York, ON, Canada) and dissolved in ethanol.

Cell culture. KP-N-TK cells have been established and cultured in Dulbecco's modified Eagle's medium (DMEM) containing $10 \%$ fetal bovine serum, $4 \mathrm{mM}$ L-glutamine, $100 \mathrm{U} / \mathrm{mol}$ of penicillin $\mathrm{G}$ and $100 \mu \mathrm{g} / \mathrm{ml}$ of streptomycin. The cells were incubated at the temperature of $37^{\circ} \mathrm{C}$ in a humidified atmosphere of $5 \% \mathrm{CO}_{2}$ in air $(7,8)$.

DAPI staining. Cells were cultured on 6-well plates, washed twice with PBS and fixed in 4\% paraformaldehyde (PFA) for $30 \mathrm{~min}$. After washing with PBS, the cells were incubated in $1 \mu \mathrm{g} / \mathrm{ml} \mathrm{4,6-diamidino-2-phenylindole} \mathrm{(DAPI)} \mathrm{solution} \mathrm{for}$ $30 \mathrm{~min}$ in the dark. The cells were observed using a fluorescence microscope (Zeiss, Oberköchen, Germany).

WST-8 assay. WST-8 [2-(2-methoxy-4-nitrophenyl)-3-(4nitrophenyl)-5-(2,4-disulfophenyl)-2H-tetrazolium, monosodium salt] colorimetric assay was performed using Cell Counting Kit-8 (Dojin East, Tokyo, Japan) according to the manufacturer's instructions. Cells $(5,000$ cells/well) were seeded into 96-well cell plates in $100 \mu 1$ of culture medium for $24 \mathrm{~h}$ prior to drug exposure, and then treated with various concentrations of drugs for various durations. After drug exposure for the indicated concentrations and times, the medium was discarded and replaced with $90 \mu 1$ of fresh medium. Next, $10 \mu \mathrm{l}$ of WST-8 reagent solution was added and incubated for $4 \mathrm{~h}$ at $37^{\circ} \mathrm{C}$ in an incubator. Cell viability was determined colorimetrically by the optical density (OD) at a wavelength of $450 \mathrm{~nm}$, with a microplate reader (Titertek Multiscan MCC, Dainippon Pharmaceutical, Osaka, Japan).

LDH assay. The release of lactate dehydrogenase (LDH) was evaluated using a CytoTox-ONE ${ }^{\mathrm{TM}}$ Homogeneous Membrane Integrity Assay kit (Promega Co., Madison, WI, USA) according to the manufacturer's protocol. Data were analyzed using the Student's t-test and differences from the controls were considered significant when $\mathrm{p}<0.05$.

TUNEL assay. TUNEL assay was performed using a Mebstain $^{\mathrm{TM}}$ apoptosis kit (Medical \& Biological Laboratories Co., Ltd., Nagoya, Japan) according to the manufacturer's instructions and analyzed with a FACScalibur (BD Biosciences Immunocytometry Systems, San Jose, CA), and Cell Quest software (BD Biosciences Immunocytometry). Data were analyzed using Student's t-test and differences from the controls were considered significant when $\mathrm{p}<0.05$.

Caspase-3/7 assay. The caspase-3/7 enzyme activity assay was measured using an APO-ONE ${ }^{\mathrm{TM}}$ homogeneous caspase-3/7 assay kit (Promega Co., Madison, WI, USA) according to the manufacturer's protocol and analyzed with a fluorescence microplate reader (GENious ${ }^{\mathrm{TM}}$, TECAN, Mannedorf/Zurich, Switzerland). Data were analyzed using Student's t-test and differences were considered significant from controls when $\mathrm{p}<0.05$.

Flow cytometric analysis. Cells were suspended in PBS containing $0.1 \%$ Triton $\mathrm{X}-100$ and $0.1 \%$ RNase A. The suspension was filtered through $50-\mu \mathrm{m}$ nylon mesh and nuclei were stained with $50 \mathrm{mg} / \mathrm{ml}$ of propidium iodide (PI). The DNA content was analyzed with a FACScalibur (BD Biosciences Immunocytometry Systems), and Cell Quest software (BD Biosciences Immunocytometry). Data were analyzed using Student's t-test and differences from the controls were considered significant when $\mathrm{p}<0.05$. Pan-caspase inhibitor zVADfmk was obtained from R\&D systems (Minneapolis, MN, USA).

Protein extraction and Western blotting. Cells were scraped and centrifuged at $300 \mathrm{x} \mathrm{g}$ for $5 \mathrm{~min}$. After the supernatant was aspirated, cell pellets were washed twice with ice-cold PBS, and were suspended with lysis buffer (50 mM Tris- $\mathrm{HCl}$, $\mathrm{pH} 7.5,1 \%$ SDS). The suspension was homogenized by sonication and centrifuged at $15000 \mathrm{x}$ g for $15 \mathrm{~min}$ at $4^{\circ} \mathrm{C}$. The supernatant was collected and kept for analysis. The extracts $(50 \mu \mathrm{g})$ were separated with $12 \%$ SDS-PAGE, and transferred to PVDF membrane. Monoclonal antibodies to $ß$-actin (Sigma-Aldrich, MO, USA), caspase-7 (R\&D Systems), caspase-8 (Medical \& Biological Laboratories), caspase-9 (Medical \& Biological Laboratories) and caspase-10 (Medical $\&$ Biological Laboratories) were used as probes. Signals were detected using an ECL Western blot analysis system (Amersham Pharmacia, Biotech, Inc., NJ, USA).

\section{Results}

LB-18 causes cell death in human neuroblastoma KP-N-TK cells. We first investigated the effect of LB-18 on the growth 
A

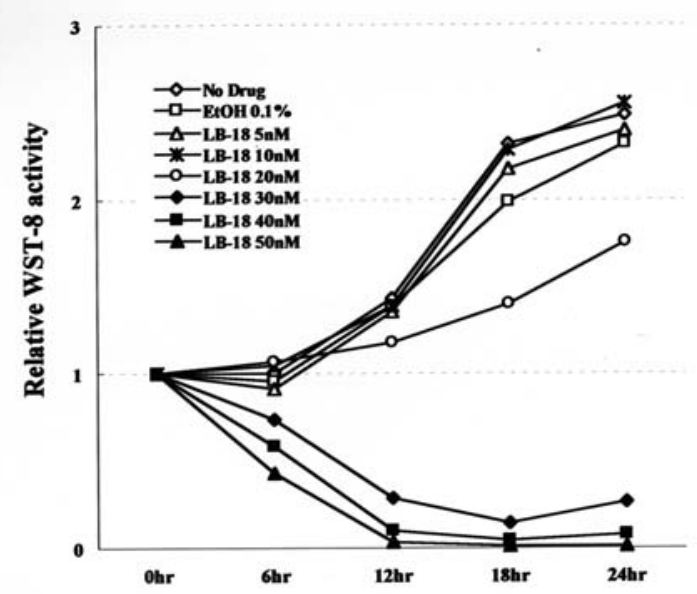

B

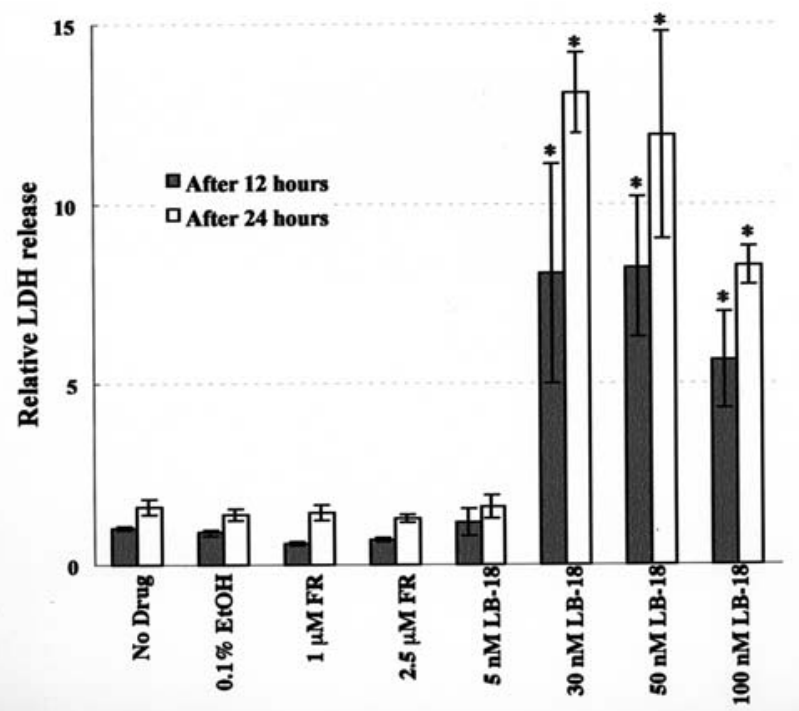

Figure 2. LB-18 inhibited cell growth and induced cell death in human neuroblastoma KP-N-TK cells. (A) The effect of LB-18 on cell growth was determined using a WST-8 colorimetric assay. Cells were treated with various concentrations of LB-18 or equivalent ethanol (EtOH) for 6-24 h. Viable cells were assayed using a WST-8 colorimetric assay, as described in Materials and methods. (B) The cell death caused by LB-18, fenretinide (FR) or equivalent ethanol (EtOH) was determined by measuring the release of LDH from the dead cells. Cells were treated with various concentrations of LB-18 or FR for 12 or $24 \mathrm{~h}$. The release of LDH from the cells was determined as described in Materials and methods (means $\pm \mathrm{SD}, \mathrm{n}=3$ ). Each value was compared with the control $(0.1 \% \mathrm{EtOH}) .{ }^{*} \mathrm{P}<0.05$.

of human neuroblastoma KP-N-TK cells. The dose- and timedependent effects of LB-18 on cell growth were examined using a WST-8 assay. Fig. 2A shows the growth of human neuroblastoma KP-N-TK cells in the presence or absence of various concentrations of LB-18. KP-N-TK cells treated with LB-18 displayed dose- and time-dependent decreases in WST- 8 activity. Treatment with LB-18 at $30 \mathrm{nM}$ or more significantly reduced viable cells. We next performed a lactate dehydrogenase (LDH) assay to analyze cell death. LB-18 increased the release of LDH into the media, while $\mathrm{N}-(4-$ hydroxyphenyl) retinamide (fenretinide), which is a wellknown agent causing apoptosis in KP-N-TK cells (8), did not increase LDH release (Fig. 2B). These results suggest that LB-18 causes cell death in human neuroblastoma KP-N-TK cells.
No Drug

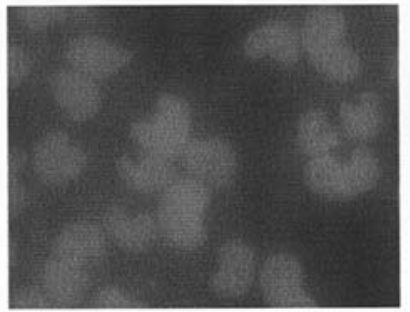

LB-18 $20 \mathrm{nM}$

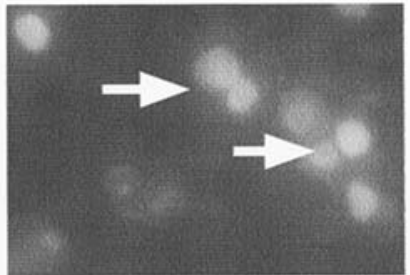

LB-18 $100 \mathrm{nM}$

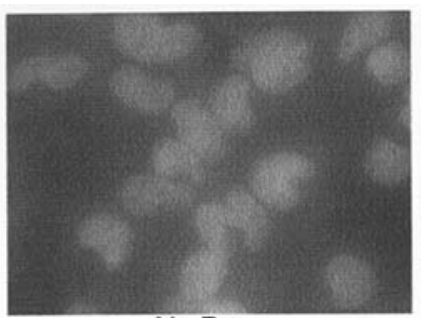

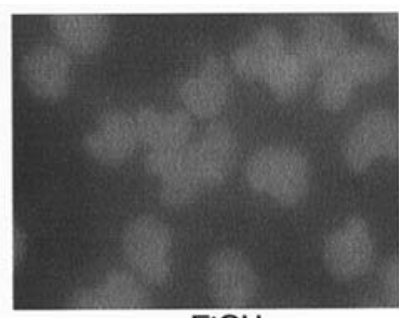

$\mathrm{EtOH}$

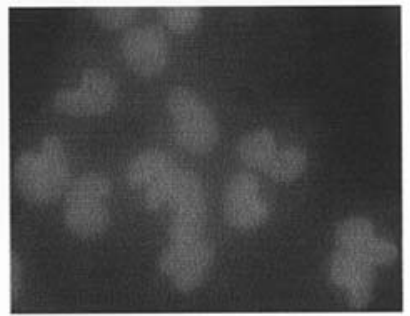

LB-18 $50 \mathrm{nM}$

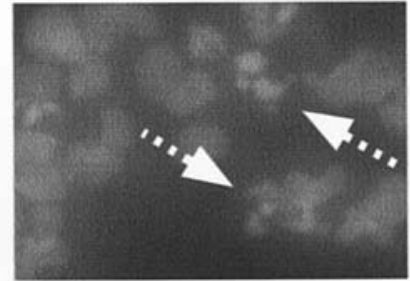

FR $1.0 \mu \mathrm{M}$
Figure 3. Nuclei of KP-N-TK cells were treated with various concentrations of LB-18, $1.0 \mu \mathrm{M}$ fenretinide (FR), or equivalent ethanol (EtOH) for $48 \mathrm{~h}$, and were stained with DAPI. White arrows indicate the condensed nuclei (treated with LB-18 at $100 \mathrm{nM}$ ). White dotted arrows indicate the condensed and fragmented nuclei (treated with FR at $1.0 \mu \mathrm{M}$ ). DAPI staining was performed as described in Materials and methods.

Features of cell death induced by LB-18. To determine whether LB-18-induced cell death is apoptotic or not, cells were exposed to $20-100 \mathrm{nM}$ LB-18 for $48 \mathrm{~h}$ and observed by DAPI staining (Fig. 3). KP-N-TK cells treated with $1.0 \mu \mathrm{M}$ fenretinide displayed the typical morphological hallmarks of apoptosis, including intense shrinkage, chromatin condensation and nuclear fragmentation. In contrast, no significant change occurred in cells treated with LB-18 at 20 or $50 \mathrm{nM}$. LB-18 at $100 \mathrm{nM}$ caused chromatin condensation but not nuclear fragmentation. In TUNEL assay, which measures DNA strand breaks in individual cells, LB-18 at $20 \mathrm{nM}$ or more, effectively increased the TUNEL positive cells (Fig. 4). Fenretinide at $2.5 \mu \mathrm{M}$ as a positive control also increased the TUNEL positive cells $48 \mathrm{~h}$ after the treatment. To further verify if LB-18 induces DNA damage, flow cytometric analysis was carried out for cells exposed to LB-18 or fenretinide as a positive control (Fig. 5). Treatment with LB-18 or fenretinide increased the sub-G0/G1 peak. Next, we examined whether benzyloxycarbonyl-ValAla-Asp $\left(\mathrm{OCH}_{3}\right)-\mathrm{CH}_{2} \mathrm{~F}$ ( $\mathrm{zVAD}$-fmk), which is a pan-caspase inhibitor and interrupts apoptosis efficiently, decreases the sub-G0/G1 population induced by LB-18 or fenretinide. zVAD-fmk did not inhibit the induction of the sub-G0/G1 peak by LB-18, whereas zVAD-fmk inhibited the induction of the sub-G0/G1 peak by fenretinide. These data indicate that LB-18 induces cell death, not showing typical features of 


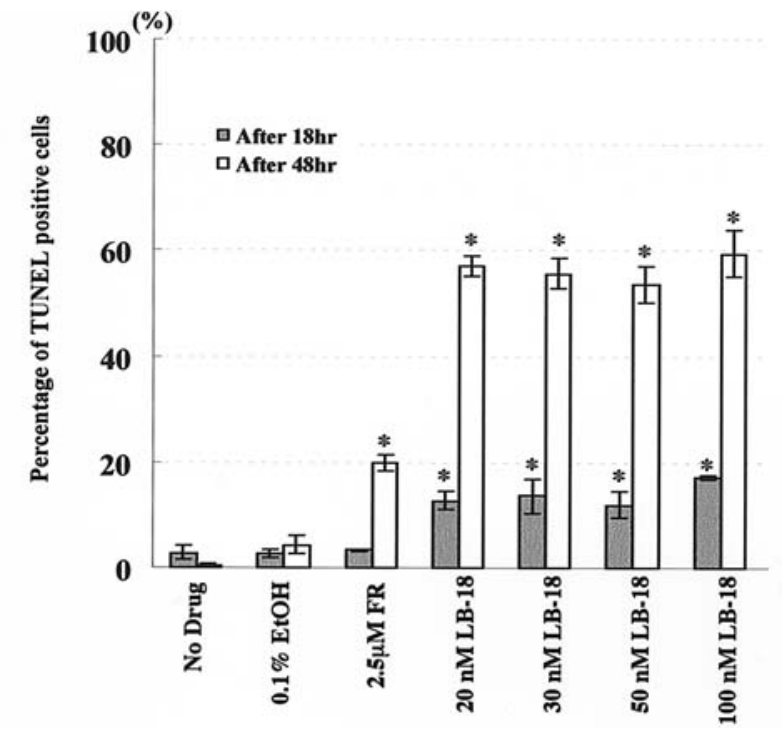

Figure 4. Assessment of DNA damage by TUNEL assay. KP-N-TK cells were treated with various concentrations of LB-18, $2.5 \mu \mathrm{M}$ fenretinide (FR), or equivalent ethanol (EtOH) for 18 or $48 \mathrm{~h}$, harvested and fixed, and then TUNEL assay was performed as described in Materials and methods. The percentage of TUNEL positive cells is shown (means $\pm \mathrm{SD}, \mathrm{n}=3$ ). Each value was compared with the control $(0.1 \% \mathrm{EtOH}) .{ }^{*} \mathrm{P}<0.05$.

apoptosis, and suggest that the death induced by LB-18 is caspase-independent.

\section{LB-18-induced cell death is not associated with caspase} activation. Caspases, a family of cystein proteases, are an integral part of the apoptotic pathway (9). To examine the effects of LB-18 or fenretinide on the activities of the caspases, we performed Western blot analysis of caspases 9, 8, 10 and 7 when LB-18 or fenretinide was added at the indicated concentrations (Fig. 6A). In this cell line, the expression of caspase 10 could not be detected in KP-N-TK cells (data not shown). Fenretinide activated caspases 9, 8 and 7. In contrast, there were no obvious changes in any caspases when treated with various concentrations of LB-18. Further, we measured the caspase-3/7 activity using cleavage of the DEVD-peptide, the substrate of caspase 3/7. The amount of cleaved DEVDpeptide increased in the cells treated with fenretinide but not with LB-18 (Fig. 6B). These results are consistent with the result that zVAD-fmk could not block the induction of the sub-G0/G1 population (Fig. 5) and indicate that the death induced by LB-18 is likely to be caspase-independent and not typical apoptotic cell death.

\section{Discussion}

LB-18 has been synthesized from LB-A and found to be the most effective in inducing cellular differentiation in mouse neuroblastoma Neuro2A cells (3-6). In the present study, in contrast, LB-18 caused marked cell death in human neuroblastoma KP-N-TK cells. In addition, we found that LB-18 similarly caused cytotoxicity in human neuroblastoma cell lines, KP-N-TK (7), KP-N-DZ (7), SH-SY5Y and GOTO cells, and found that the $\mathrm{IC}_{50}$ of LB-18 was different in each cell line (data not shown). It is known that amplification of the $\mathrm{N}-m y c$ proto-oncogene $(M Y C N)$ is the most important
A

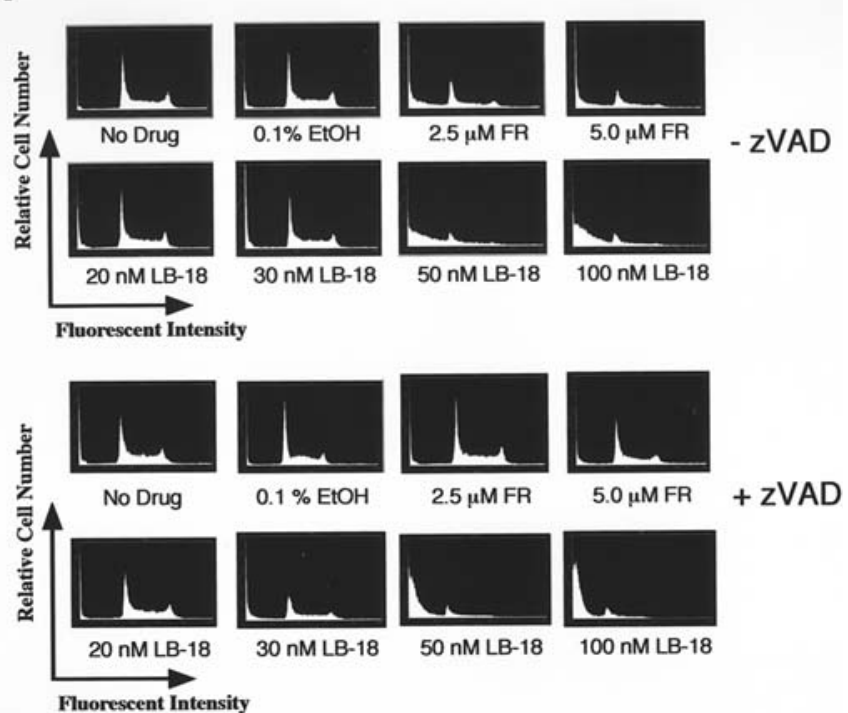

B

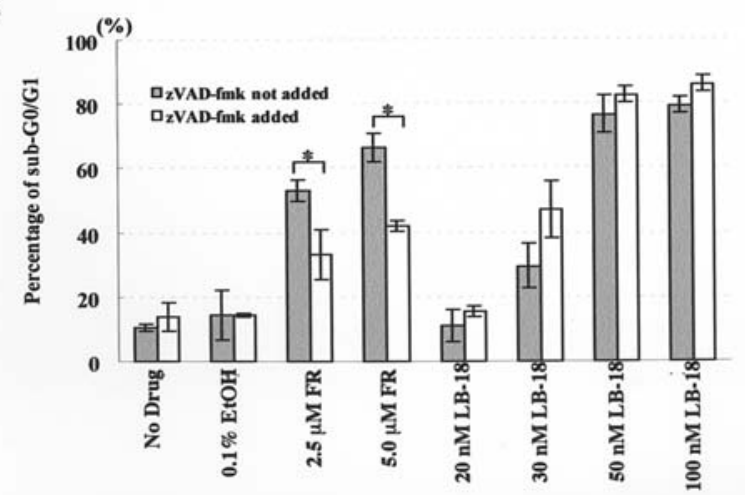

Figure 5. Assessment of cellular DNA contents by flow cytometric analysis. After incubation for $48 \mathrm{~h}$ with $20-100 \mathrm{nM} \mathrm{LB}-18,2.5$ or $5.0 \mu \mathrm{M}$ fenretinide as a positive control or equivalent ethanol $(0.1 \%)$ with or without zVADfmk, a pan-caspase inhibitor, cells were collected and their isolated nuclei were analyzed by flow cytometry as described in Materials and methods. (A) Representative flow cytometry histogram patterns. Upper panels, without zVAD-fmk. Lower panels, with zVAD-fmk. (B) The percentage of sub-G0/G1 populations analyzed using Cell Quest software. The means of experiments are shown (means $\pm \mathrm{SD}, \mathrm{n}=3$ ). ${ }^{*} \mathrm{P}<0.05$.

genetic feature of advanced-stage neuroblastoma and an adverse prognostic indicator (10-13). Only $30 \mathrm{nM}$ of LB-18 caused marked cell death in KP-N-TK cells with MYCN amplification, which raises the possibility that LB-18 is useful for treatment of human neuroblastoma with $M Y C N$ amplification (data not shown).

We found several apoptotic features in LB-18 that induce cell death, such as DNA damage and chromosome condensation. Flow cytometric analysis and TUNEL assay suggest that LB-18 at 20 or $30 \mathrm{nM}$ or more caused nuclear DNA damage (Figs. 4 and 5). On the other hand, when observed with DAPI staining, the nuclei of the cells treated with 20,50 or $100 \mathrm{nM}$ of LB-18 did not show nuclear fragmentation, though only chromosome condensation was observed at $100 \mathrm{nM}$ of LB-18 (Fig. 3). The results indicate that LB-18 causes DNA damage but not nuclear fragmentation, which is one of the well-known features of apoptosis.

In agreement with the above results, we found that the cell death induced by LB-18 is independent of the activation 


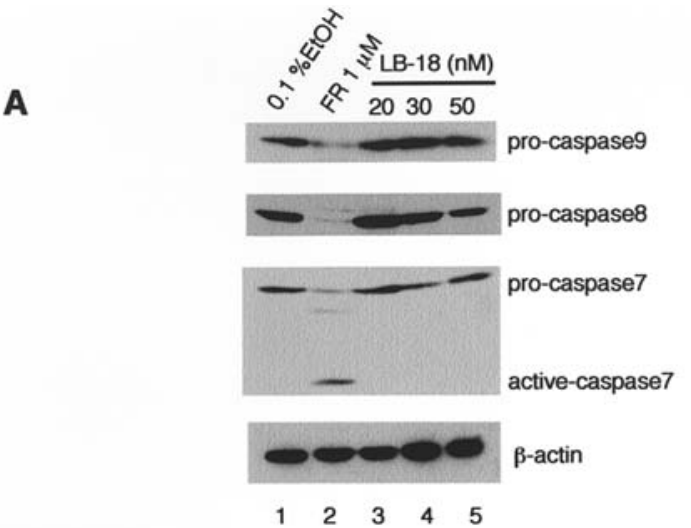

B

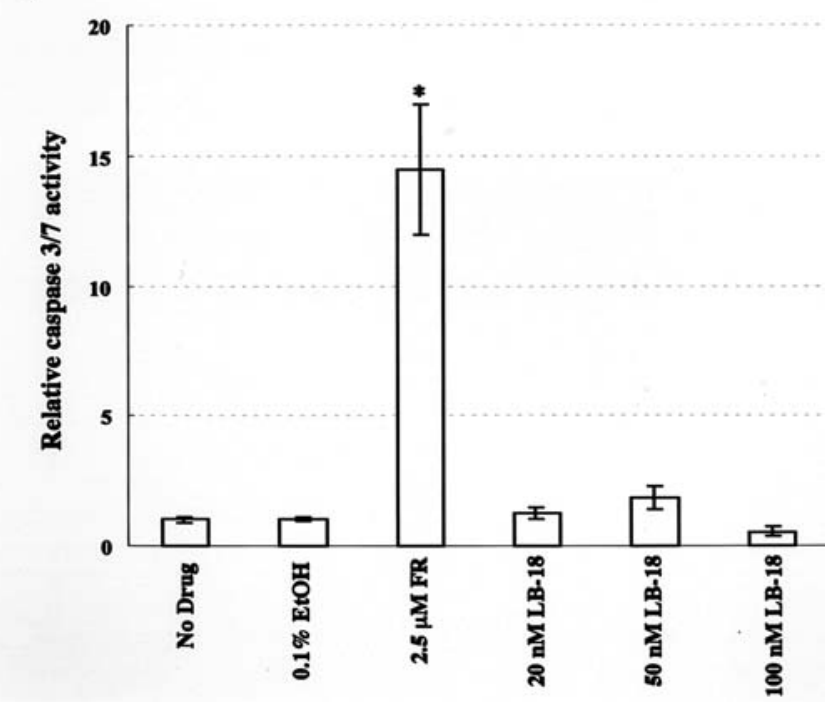

Figure 6. The effect of LB-18 is independent of activation of caspases. (A) KP-N-TK cells were treated with the indicated concentrations of LB-18, $1 \mu \mathrm{M}$ of fenretinide (FR) as a positive control or equivalent ethanol $(0.1 \%)$ for $24 \mathrm{~h}$, and the expression of caspase- $9,-8$, and -7 proteins was examined by Western blotting, as described in Materials and methods. $\beta$-actin was chosen as a loading control. (B) KP-N-TK cells were treated with the indicated concentrations of LB-18, $2.5 \mu \mathrm{M}$ of fenretinide, or equivalent ethanol $(0.1 \%)$ for $24 \mathrm{~h}$, and then the caspase-3/7 activity was determined as described in Materials and methods. The means of experiments are shown (means \pm SD, $\mathrm{n}=3)$. Each value was compared with the control $(0.1 \% \mathrm{EtOH}) .{ }^{*} \mathrm{P}<0.05$.

of caspases (Figs. 5 and 6). Caspases 3 and 7 are executive caspases, i.e. 'the final exit of apoptosis' (9). Fig. 6B shows that capase-3/7 activity was not activated significantly by LB-18 treatment. Further, we could not detect the activation of any caspases by Western blotting experiments (Fig. 6A). The data are consistent with the result that the pan-caspase inhibitor, zVAD-fmk, had no protective effect for KP-N-TK cells treated with LB-18 (Fig. 5). We therefore conclude that cell death induced by LB-18 is caspase independent and not typically apoptotic, but further examination is required.

Here, we show that a novel drug, LB-18, a derivative of lembehynes derived from a marine sponge, causes cell death efficiently and caspase-independently in human neuroblastoma cells. Molecular study of caspase-independent cell death has just emerged, but with plentiful and hopeful possibilities (14-19). Although the precise molecular mechanisms of the caspase-independent cell death are controversial, the inducers, such as LB-18, of caspase-independent cell death might be beneficial in killing cancer cells that have acquired resistance to caspase-dependent therapy.

\section{Acknowledgements}

We thank Dr T. Yoshida for his helpful discussion and useful advice. This work was partly supported by a Grant-in-Aid from the Japanese Ministry of Education, Culture, Sports, Science and Technology.

\section{References}

1. Matthay KK and Castleberry RP: Treatment of advanced neuroblastoma. The US experience. In: Neuroblastoma. Brodeur GM, Sawada T, Tsuchida Y and Voute PA (eds). Elsevier Science Publishers B.V., Amsterdam, pp417-436, 2000.

2. Aoki S, Matsui K, Tanaka K, Satari R and Kobayashi M: Lembehyne A, a novel neuritogenic polyacetylene, from a marine sponge of Haliclona sp. Tetrahedron 56: 9945-9948, 2000.

3. Aoki S, Matsui K, Takata T, Wei H and Kobayashi M: Lembehyne $\mathrm{A}$, a spongean polyacetylene, induces neuronal differentiation in neuroblastoma cell. Biochem Biophys Res Commun 289: 558-563, 2001

4. Aoki S, Matsui K, Takata T and Kobayashi M: In situ photoaffinity labeling of the target protein for lembehyne A, a neuronal differentiation inducer. FEBS Lett 544: 223-227, 2003.

5. Murakami N, Nakajima T and Kobayashi M: Total synthesis of lembehyne A, a neuritogenic spongean polyacetylene. Tetrahedron Lett 42: 1941-1943, 2000.

6. Aoki S, Matsui K, Wei H, Murakami N and Kobayashi M: Structure-activity relationship of neuritogenic spongean acetylene alcohols, lembehynes. Tetrahedron 58: 5417-5422, 2002.

7. Kuroda H, Sugimoto T, Horii Y and Sawada T: Signaling pathway of ciliary neurotrophic factor in neuroblastoma cell lines. Med Pediatr Oncol 36: 118-121, 2001.

8. Osone S, Hosoi H, Kuwahara Y, Matsumoto Y, Iehara T and Sugimoto T: Fenretinide induces sustained-activation of JNK/p38 MAPK and apoptosis in a reactive oxygen species-dependent manner in neuroblastoma cells. Int J Cancer 112: 219-224, 2004.

9. Boatright KM and Salvesen GS: Mechanisms of caspase activation. Curr Opin Cell Biol 15: 725-731, 2003.

10. Bordow SB, Norris MD, Haber PS, Marshall GM and Haber M: Prognostic significance of MYCN oncogene expression in childhood neuroblastoma. J Clin Oncol 16: 3286-3294, 1997.

11. Gotoh T, Hosoi H, Iehara T, Kuwahara Y, Osone S, Tsuchiya K, Ohira M, Nakagawara A, Kuroda $\mathrm{H}$ and Sugimoto T: Prediction of MYCN amplification in neuroblastoma using serum DNA and real-time quantitative polymerase chain reaction. J Clin Oncol 23: 5205-5210, 2005.

12. Meitar D, Crawford SE, Rademaker AW and Cohn SL: Tumor angiogenesis correlates with metastatic disease, N-myc amplification, and poor outcome in human neuroblastoma. J Clin Oncol 14: 405-414, 1996

13. Ribatti D, Raffaghello L, Pastorino F, Nico B, Brignole C, Vacca A and Ponzoni M: In vivo angiogenic activity of neuroblastoma correlates with MYCN oncogene overexpression. Int J Cancer 102: 351-354, 2002.

14. Kitanaka C, Kato K, Ijiri R, Sakurada K, Tomiyama A, Noguchi K, Nagashima Y, Nakagawara A, Momoi T, Toyoda Y, Kigasawa H, Nishi T, Shirouzu M, Yokoyama S, Tanaka Y and Kuchino Y: Increased Ras expression and caspase-independent neuroblastoma cell death: possible mechanism of spontaneous neuroblastoma regression. J Natl Cancer Inst 94: 358-368, 2002.

15. Okada H and Mak TW: Pathways of apoptotic and non-apoptotic death in tumour cells. Nat Rev Cancer 4: 592-603, 2004.

16. Kitanaka $\mathrm{C}$ and Kuchino $\mathrm{Y}$ : Caspase-independent programmed cell death with necrotic morphology. Cell Death Differ 6: 508-515, 1999.

17. Kim R, Emi M and Tanabe K: Caspase-dependent and -independent cell death pathways after DNA damage (Review). Oncol Rep 14: 595-599, 2005.

18. Kroemer G and Martin SJ: Caspase-independent cell death. Nat Med 11: 725-730, 2005

19. Broker LE, Kruyt FA and Giaccone G: Cell death independent of caspases: A review. Clin Cancer Res 11: 3155-3162, 2005. 